\title{
Characteristics and Outcome of Patients with Early Complete Neurological Recovery after Thrombolysis for Acute Ischemic Stroke
}

\author{
C. Blinzler L. Breuer H.B. Huttner P.D. Schellinger S.Schwab M. Köhrmann \\ Department of Neurology, University of Erlangen-Nuremberg, Erlangen, Germany
}

\section{Key Words}

Complete recovery $\cdot$ Tissue plasminogen activator •

Acute ischemic stroke $\cdot$ Thrombolysis

\begin{abstract}
Background: Recombinant tissue plasminogen activator (rt$\mathrm{PA}$ ) is the only approved specific therapy for acute ischemic stroke. This study analyzes demographic and clinical characteristics of patients with early complete neurological recovery after thrombolysis. Methods: Data of 320 consecutive patients treated with rt-PA within $3 \mathrm{~h}$ of stroke onset at our facility between April 2006 and March 2009 were extracted from our prospective institutional stroke and thrombolysis database. Baseline demographic parameters, risk factors, clinical characteristics as well as neuroradiologic findings of patients with complete recovery $24 \mathrm{~h}$ after treatment and at hospital discharge were analyzed. Outcome was evaluated using the modified Rankin Scale at 90 days. Results: Thirty patients (9.4\%) were asymptomatic $24 \mathrm{~h}$ after thrombolysis and $70(22 \%)$ at hospital discharge. Patients with complete recovery were younger, more often male, had milder stroke symptoms, less often cardioembolic strokes, fewer bleeding complications and more often normal follow-up imaging. In addition, in-hospital time was shorter and these patients retained a better functional outcome at 90 days. Only 1 patient who had completely recovered at hospital discharge died during the follow-up time. In multivariate regression analy-
\end{abstract}

sis, only the National Institute of Health Stroke Score (NIHSS) on admission was predictive for complete recovery at both examined time points. Conclusion: Rapid complete recovery can be achieved in up to a fifth of acute stroke patients treated with thrombolysis. These patients are younger and have milder strokes, less often with cardioembolic origin. Better outcome and lower mortality are sustained at 3 months.

Copyright $\odot 2010$ S. Karger AG, Basel

\section{Background}

Recombinant tissue plasminogen activator (rt-PA) is currently the only approved therapy for acute ischemic stroke. After systemic thrombolysis, great variation in symptom recovery can be observed. In daily practice, some stroke patients greatly benefit from rt-PA and recover normal function shortly after application, suggesting successful recanalization. The majority of thrombolysis studies investigated long-term clinical outcome after 3 months or predictors of neurologic deterioration. There are very few data about determinants of early complete recovery after treatment with rt-PA. This study was performed to analyze demographic, clinical and radiological characteristics of patients with complete neurological recovery within $24 \mathrm{~h}$ after intravenous thrombolysis and at hospital discharge.

\section{KARGER}

Fax +41613061234 E-Mail karger@karger.ch www.karger.com
Dr. med. Christian Blinzler

Department of Neurology, University of Erlangen-Nuremberg

Schwabachanlage 6, DE-91054 Erlangen (Germany)

Tel. +49 91318544 156, Fax +49 91318536597

E-Mail christian.blinzler@uk-erlangen.de 


\section{Methods}

\section{Patient Selection, Treatment and Evaluation of Outcome}

The Erlangen Stroke and Thrombolysis Database is a prospective database of all patients with acute ischemic stroke treated at our institution (University Hospital Erlangen, Germany). It was established in April 2006 and contains baseline demographic and stroke-related data as well as treatment specifics, imaging information for each patient. Data of 1,661 stroke patients were included into the database between April 2006 and March 2009. Systemic thrombolysis was performed in 377 patients (thrombolysis rate $22.7 \%$ ). To allow comparison with other studies, patients treated outside the 3 -hour time window $(n=54)$ and with symptoms of nonischemic origin - according to the final diagnosis were excluded from the analyses $(n=3)$. Thus 320 patients treated with intravenous thrombolysis within a 3 -hour time window were included into the present study. A National Institute of Health Stroke score (NIHSS) is recorded 3 times daily by a stroke neurologist certified for NIHSS evaluation. Ninety-day outcome is evaluated by a neurologist as part of the general database independently of the present study. A modified Rankin Scale (mRS) score is derived using a semi-structured interview either in person or by telephone (patient, relatives) by a physician certified for mRS evaluation. The semi-structured interview was conducted on the basis of the mRS-SI [1], asking for the necessity of constant care, assistance for activities of daily living, ability to look after own affairs and restrictions in usual duties and activities.

In a first analysis, all patients with complete recovery at $24 \mathrm{~h}$ were compared with those with persisting symptoms. The same analysis was then carried out for patients asymptomatic at hospital discharge. Complete recovery was defined as no persisting symptoms from the present stroke. Symptomatic intracranial hemorrhage was defined using the ECASS-III criteria. All other intracranial hemorrhages were rated as asymptomatic.

\section{Statistical Analysis}

Statistical analysis was performed using PASW Statistics 17 (SPSS Inc., Chicago, Ill., USA). All data were tested for normality. Continuous data are expressed as mean and standard deviation or as median and interquartile range as appropriate; dichotomized variables are shown as numbers and percentages. Intergroup differences were assessed using the $t$ test for normally distributed items, the Mann-Whitney U test for values with nonGaussian distribution and the $\chi^{2}$ test for dichotomous variables. Based on the results of univariate analysis, a logistic regression was performed including the factors that were associated with symptom recovery in the univariate model.

\section{Results}

Thirty patients (9.4\%) were asymptomatic $24 \mathrm{~h}$ after treatment. These patients were younger $(\mathrm{p}=0.025)$ and more often males $(\mathrm{p}=0.032)$. Regarding risk factors, there was a lower rate of atrial fibrillation $(p=0.030)$ corresponding to fewer cardioembolic strokes. On admission, this patient group had a lower baseline NIHSS $(\mathrm{p}<$
$0.001)$ with a lower incidence of impaired consciousness $(\mathrm{p}=0.002)$ and neglect $(\mathrm{p}=0.040)$. Follow-up imaging was less likely to show ischemic changes $(p=0.037)$. The early recovery led to shorter in-hospital time $(\mathrm{p}<0.001)$, and the functional outcome $(\mathrm{p}<0.001)$ and mortality rates were more favorable. Complete patient characteristics as well as group comparisons are shown in table 1 .

Seventy patients (22\%) achieved full symptom recovery during their hospital stay. Again, asymptomatic patients had a lower rate of atrial fibrillation. The median baseline NIHSS was lower and temperature at presentation higher $(\mathrm{p}=0.007)$ than in patients without complete recovery. However, the absolute difference in temperature between the groups was small (median 37.0 vs. $36.9^{\circ} \mathrm{C}$ ). Patients had a lower rate of facial palsy $(\mathrm{p}=0.003)$, paresis of the upper and lower extremities (both $<0.001$ ), sensory loss $(\mathrm{p}=0.022)$, neglect $(\mathrm{p}<0.001)$ and impaired consciousness $(\mathrm{p}<0.001)$. As in the patients with complete recovery within $24 \mathrm{~h}$, patients that were asymptomatic at hospital discharge had a lower rate of imaging-proven infarction $(\mathrm{p}=0.037)$. In-hospital time was shortened $(\mathrm{p}<0.001)$ and, again, the functional outcome and mortality rates were more favorable. Complete patient characteristics as well as group comparisons are shown in table 2 .

Overall, symptomatic intracranial hemorrhage occurred in 15 patients (4.7\%). It was observed neither in the group with very early complete recovery $(<24 \mathrm{~h})$ nor in the group with early complete recovery.

In multivariate regression analysis, only NIHSS on admission was predictive of complete recovery at both examined time points. In addition, normal follow-up imaging independently predicted complete recovery at hospital discharge. The results of the multivariate analysis are shown in table 3.

\section{Discussion}

Thrombolysis using rt-PA is the only approved reperfusion therapy for acute ischemic stroke. In daily practice, some stroke patients demonstrate dramatic early improvement of their symptoms and totally recover normal function shortly after drug administration. There are very few data published regarding patients without any disability shortly after symptom onset and during hospital stay.

Regarding baseline characteristics, younger age and lower admission NIHSS were found to be associated with complete early recovery. These factors were previously shown to predict improved outcome at 90 days in other studies. In a multivariate analysis of over 6,000 patients 
Table 1. Demographics and baseline characteristics $24 \mathrm{~h}$ after symptom onset

\begin{tabular}{|c|c|c|c|}
\hline & Asymptomatic $(\mathrm{n}=30)$ & Symptomatic $(\mathrm{n}=290)$ & $\mathrm{p}$ value \\
\hline \multicolumn{4}{|l|}{ Demographics } \\
\hline Age, years & 69 (IQR 56-82) & 73 (IQR 64-84) & $0.025^{*}$ \\
\hline Female & $7(23 \%)$ & $131(45 \%)$ & $0.032^{*}$ \\
\hline \multicolumn{4}{|l|}{ Clinical characteristics } \\
\hline Days in hospital & 6 (IQR 5-8) & 9 (IQR 6-13) & $<0.001^{*}$ \\
\hline Arterial hypertension & $23(77 \%)$ & $237(82 \%)$ & 0.468 \\
\hline Atrial fibrillation & $6(20 \%)$ & $118(41 \%)$ & $0.030^{*}$ \\
\hline Hypercholesterolemia & $19(63 \%)$ & $161(56 \%)$ & 0.446 \\
\hline History of smoking & $3(10 \%)$ & $35(12 \%)$ & 1.000 \\
\hline Diabetes mellitus & $8(27 \%)$ & $108(37 \%)$ & 0.320 \\
\hline Patent foramen ovale & $2(7 \%)$ & $11(4 \%)$ & 0.349 \\
\hline History of stroke & $3(10 \%)$ & $45(16 \%)$ & 0.593 \\
\hline Coronary heart disease & $8(27 \%)$ & $67(23 \%)$ & 0.655 \\
\hline Myocardial infarction & $2(7 \%)$ & $36(13 \%)$ & 0.553 \\
\hline Peripheral arterial occlusive disease & $5(17 \%)$ & $29(10 \%)$ & 0.344 \\
\hline \multicolumn{4}{|l|}{ Stroke characteristics } \\
\hline NIHSS on admission & 5 (IQR 3-7) & 10 (IQR 5-15) & $<0.001^{*}$ \\
\hline Left hemisphere & $19(63 \%)$ & $159(55 \%)$ & 0.442 \\
\hline Right hemisphere & $11(37 \%)$ & $105(36 \%)$ & 1.000 \\
\hline Brainstem/cerebellar & 0 & $20(7 \%)$ & 0.236 \\
\hline Facial palsy & $17(57 \%)$ & $210(72 \%)$ & 0.090 \\
\hline Paresis upper extremity & $23(77 \%)$ & $245(85 \%)$ & 0.297 \\
\hline Paresis lower extremity & $19(63 \%)$ & $211(73 \%)$ & 0.290 \\
\hline Sensory loss & $11(37 \%)$ & $143(50 \%)$ & 0.122 \\
\hline Dysarthria & $12(40 \%)$ & $142(49 \%)$ & 0.443 \\
\hline Aphasia & $13(43 \%)$ & $140(48 \%)$ & 0.702 \\
\hline Neglect & $1(3 \%)$ & $55(19 \%)$ & $0.040^{*}$ \\
\hline Impaired consciousness & 0 & $59(20 \%)$ & $0.002^{*}$ \\
\hline Hemianopia & 0 & $5(2 \%)$ & 1.000 \\
\hline Symptomatic intracranial hemorrhage & 0 & $15(5 \%)$ & 0.377 \\
\hline Asymptomatic intracranial hemorrhage & $2(7 \%)$ & $15(5 \%)$ & 0.666 \\
\hline Time window, $\min$ & 120 (IQR 90-149) & 115 (IQR 85-150) & 0.828 \\
\hline mRS after 3 months & 0 (IQR 0-1) & 3 (IQR 1-4) & $<0.001^{*}$ \\
\hline Follow-up mRS 0-1 & $24(80 \%)$ & $75(26 \%)$ & $<0.001^{*}$ \\
\hline Follow-up mRS 0-2 & $26(87 \%)$ & $112(39 \%)$ & $<0.001^{*}$ \\
\hline Death within 3 months & 0 & $41(15 \%)$ & $0.021^{*}$ \\
\hline Ischemia in CT scan & $18(60 \%)$ & $229(79 \%)$ & $0.037^{*}$ \\
\hline \multicolumn{4}{|l|}{ Vital signs } \\
\hline Admission temperature, ${ }^{\circ} \mathrm{C}$ & 37.1 (IQR 36.7-37.4) & 36.9 (IQR 36.5-37.3) & 0.176 \\
\hline Admission blood glucose, $\mathrm{mg} / \mathrm{dl}$ & 108.5 (IQR 92-135) & 118 (IQR 98-146) & 0.189 \\
\hline Cholesterol, mg/dl & $190.77( \pm 38.00)$ & $193.01( \pm 52.05)$ & 0.819 \\
\hline Systolic blood pressure, $\mathrm{mm} \mathrm{Hg}$ & $155.67( \pm 23.57)$ & $158.81( \pm 26.35)$ & 0.409 \\
\hline Diastolic blood pressure, $\mathrm{mm} \mathrm{Hg}$ & $87.80( \pm 12.12)$ & $86.52( \pm 17.99)$ & 0.705 \\
\hline
\end{tabular}

$\mathrm{IQR}=$ Interquartile range. ${ }^{*} \mathrm{p}<0.05$.

treated with rt-PA (SITS-MOST registry), Wahlgren et al. [2] showed that older age and a high NIHSS at baseline were significantly related to poor outcome. This was in concordance with the results of the multicenter stroke survey by Demchuk et al. [3], which demonstrated that milder baseline stroke severity was the most important predic- tor of a favorable outcome after thrombolysis. Additionally, clinical signs of severe stroke, such as impaired consciousness and neglect, were found more frequently in patients with persisting symptoms independently of examination time in this study. It is therefore not remarkable that patients with mild symptoms at baseline, indicating 
Table 2. Demographics and baseline characteristics on hospital discharge

\begin{tabular}{|c|c|c|c|}
\hline & Asymptomatic $(\mathrm{n}=70)$ & Symptomatic $(\mathrm{n}=250)$ & $\mathrm{p}$ value \\
\hline \multicolumn{4}{|l|}{ Demographics } \\
\hline Age, years & 70.5 (IQR 59-78) & 72.5 (IQR 62-81) & 0.245 \\
\hline Female & $26(37 \%)$ & $112(45 \%)$ & 0.277 \\
\hline \multicolumn{4}{|l|}{ Clinical characteristics } \\
\hline Days in hospital & 7 (IQR 5-8) & 10 (IQR 7-13) & $<0.001^{*}$ \\
\hline Arterial hypertension & $59(84 \%)$ & $201(80 \%)$ & 0.603 \\
\hline Atrial fibrillation & $17(24 \%)$ & $107(43 \%)$ & $0.005^{*}$ \\
\hline Hypercholesterolemia & $45(64 \%)$ & $135(54 \%)$ & 0.136 \\
\hline History of smoking & $9(13 \%)$ & $29(12 \%)$ & 0.835 \\
\hline Diabetes mellitus & $25(36 \%)$ & $91(36 \%)$ & 1.000 \\
\hline Patent foramen ovale & $2(3 \%)$ & $11(4 \%)$ & 0.741 \\
\hline History of stroke & $9(13 \%)$ & $39(16 \%)$ & 0.706 \\
\hline Coronary heart disease & $17(25 \%)$ & $58(23 \%)$ & 0.873 \\
\hline Myocardial infarction & $9(13 \%)$ & $29(12 \%)$ & 0.835 \\
\hline Peripheral arterial occlusive disease & $9(13 \%)$ & $25(10 \%)$ & 0.512 \\
\hline \multicolumn{4}{|l|}{ Stroke characteristics } \\
\hline NIHSS on admission & 5 (IQR 3-7) & 11 (IQR 6-15) & $<0.001^{*}$ \\
\hline Left hemisphere & $19(63 \%)$ & $159(55 \%)$ & 0.442 \\
\hline Right hemisphere & $11(37 \%)$ & $105(36 \%)$ & 1.000 \\
\hline Brainstem/cerebellar & 0 & $20(7 \%)$ & 0.236 \\
\hline Facial palsy & $38(56 \%)$ & $188(75 \%)$ & $0.003^{*}$ \\
\hline Paresis upper extremity & $45(64 \%)$ & $223(89 \%)$ & $<0.001^{*}$ \\
\hline Paresis lower extremity & $38(54 \%)$ & $192(77 \%)$ & $<0.001^{*}$ \\
\hline Sensory loss & $25(36 \%)$ & $129(52 \%)$ & $0.021^{*}$ \\
\hline Dysarthria & $30(43 \%)$ & $124(50 \%)$ & 0.344 \\
\hline Aphasia & $33(47 \%)$ & $120(48 \%)$ & 0.893 \\
\hline Neglect & $3(4 \%)$ & $53(21 \%)$ & $0.001^{*}$ \\
\hline Impaired consciousness & $4(6 \%)$ & $55(22 \%)$ & $0.001^{*}$ \\
\hline Hemianopia & $1(1 \%)$ & $5(2 \%)$ & 1.000 \\
\hline Symptomatic intracranial hemorrhage & 0 & $15(6 \%)$ & $0.048^{*}$ \\
\hline Asymptomatic intracranial hemorrhage & $3(4 \%)$ & $14(6 \%)$ & 1.000 \\
\hline Time window & 120 (IQR 90-149) & 110 (IQR 85-150) & 0.559 \\
\hline mRS after 3 months & $0($ IQR $0-1)$ & 3 (IQR 2-4) & $<0.001^{*}$ \\
\hline Follow-up mRS 0-1 & $52(75 \%)$ & $40(18 \%)$ & $<0.001^{*}$ \\
\hline Follow-up mRS 0-2 & $56(81 \%)$ & $74(33 \%)$ & $<0.001^{*}$ \\
\hline Death within 3 months & $1(1 \%)$ & $40(17 \%)$ & $<0.001^{*}$ \\
\hline Ischemia in CT scan & $37(53 \%)$ & $210(84 \%)$ & $<0.001^{*}$ \\
\hline \multicolumn{4}{|l|}{ Vital signs } \\
\hline Admission temperature, ${ }^{\circ} \mathrm{C}$ & 37.0 (IQR 36.8-37.4) & 36.9 (IQR 36.4-37.2) & $0.007^{*}$ \\
\hline Admission blood glucose, $\mathrm{mg} / \mathrm{dl}$ & $108.5($ IQR 91-137) & 118 (IQR 100-146) & 0.056 \\
\hline Cholesterol, mg/dl & $194.38( \pm 52.58)$ & $192.32( \pm 50.36)$ & 0.768 \\
\hline Systolic blood pressure, $\mathrm{mm} \mathrm{Hg}$ & $159.74( \pm 21.36)$ & $159.33( \pm 27.32)$ & 0.906 \\
\hline Diastolic blood pressure, $\mathrm{mm} \mathrm{Hg}$ & $88.06( \pm 15.39)$ & $86.24( \pm 18.09)$ & 0.445 \\
\hline
\end{tabular}

$\mathrm{IQR}=$ Interquartile range. ${ }^{*} \mathrm{p}<0.05$.

small-size cerebral ischemia, are more likely to gain full symptom recovery. As a result of neurological recovery, time in hospital was shorter in asymptomatic patients.

Male patients were more likely to fully recover after thrombolysis in our series. The influence of sex on the outcome after thrombolysis is a topic of controversy in recent publications. In accordance with our findings, men were approximately 3 times more likely to have good functional outcomes in the GAIN study [4] and Delgato et al. [5] identified male sex as a factor for clinical improvement $48 \mathrm{~h}$ after intravenous thrombolysis. In contrast, no difference in outcome 90 days after stroke was 
Table 3. Results of multivariate regression analysis

\begin{tabular}{lllll}
\hline Time point & Variable & OR & p & $95 \%$ CI \\
\hline At 24 h & NIHSS on admission & 0.794 & $<0.001$ & $0.712-0.886$ \\
\hline At discharge & NIHSS on admission & 0.817 & $<0.001$ & $0.758-0.880$ \\
& Ischemia in CT scan & 0.365 & 0.002 & $0.192-0.693$ \\
\hline
\end{tabular}

$-2 \log$ likelihood at $24 \mathrm{~h}$ was 170.377 and 266.368 on discharge. Nagelkerkes $\mathrm{R}^{2}$ was 0.183 at $24 \mathrm{~h}$ and 0.300 on discharge. $\mathrm{OR}=$ Odds ratio; $95 \% \mathrm{CI}=95 \%$ confidence interval.

found in the CASES [6] study in 1,110 thrombolyzed patients and the pooled analysis of the NINDS, ANLANTIS and ECASS (I and II) even showed that women benefited more from rt-PA compared with men [7]. Similar results were observed by Saposnik et al. [8], who demonstrated that female sex was associated with major neurologic improvement after rt-PA.

Atrial fibrillation is a recognized predictor for more severe strokes, a worse outcome and higher mortality in affected patients. In addition, atrial fibrillation was correlated with a reduced chance of recanalization $24 \mathrm{~h}$ after treatment with alteplase as demonstrated using transcranial Doppler ultrasound in a small study by Tandberg Askevold [9] as well as in a Japanese trial [10] showing atrial fibrillation to be associated with no recanalization in serial magnetic resonance angiography. In accordance with our data, Saňák et al. [11] described a worse outcome 90 days after intravenous thrombolysis in patients with atrial fibrillation just as Kimura et al. [12], who additionally found fewer patients with dramatic improvement after 7 days in their atrial fibrillation cohort.

Slightly higher baseline temperatures were observed in asymptomatic patients on hospital discharge in our study. Interestingly, the same observation was made in the Bergen stroke study [13], which found an inverse relationship between baseline body temperature and outcome and between rt-PA treatment and conservative therapy. A high baseline temperature was associated with a favorable outcome after 1 week in thrombolized patients just as low body temperature among patients not treated with rt-PA. This might be explained by the improved activity of the protease rt-PA on clot lysis at higher temperatures, exceeding the neuroprotective effect of low body temperature shortly after rt-PA administration. However, the small absolute difference in our study, and its effect on rt-PA activity and outcome may be statistically significant but not clinically relevant.

Complete Recovery after Thrombolysis
The fact that asymptomatic patients in our study were less likely to have ischemia on follow-up CT scans raises the question whether indeed we were treating transient ischemic attacks (TIAs) in the first place. This discussion, however, is theoretical since thrombolysis aims to 'convert strokes into TIAs' and is not an option to wait and see whether symptoms resolve without treatment. Furthermore, $24 \mathrm{~h}$ after thrombolysis, $60 \%$ of asymptomatic patients had a proven infarction on their follow-up CT scans and follow-up examinations using MRI may have shown an even higher percentage of cerebral ischemia. Currently there is no convincing diagnostic method available predicting spontaneous recovery under emergency room conditions and differentiating between stroke and TIA. Our data also failed to yield solid predictive clinical factors. Among baseline characteristics, only NIHSS on admission was predictive of complete recovery in multivariate analysis. Thus no other clinical variables can guide clinicians in the acute phase. The fact that no proven ischemia on follow-up imaging predicts complete recovery at hospital discharge is of course not known at baseline but may be useful in the early hospital course. In the future, more sophisticated baseline imaging models to predict tissue fate may to some extent help in deciding on treatment.

In addition to primary TIA, uncertainty remains whether full neurological recovery may due to a nonischemic process. According to current publications, a nonischemic origin of stroke symptoms with subsequent full recovery is not frequent. In a recent Swiss study, only $2.8 \%$ of 250 patients receiving intravenous thrombolysis could be identified as stroke mimics; another university stroke center reported that $3.5 \%$ of patients treated with rt-PA had a nonischemic diagnosis [14, 15]. In our series, only 3 treated patients had diagnoses other than stroke $(0.8 \%)$.

After 3 months, a better outcome and lower mortality were recorded in patients without any disability after $24 \mathrm{~h}$ as well as on hospital discharge in this investigation. A similar finding was made in a subgroup analysis of the NINDS trial, assessing patients with neurological improvement $\geq 8$ points or an NIHSS of 0 at $24 \mathrm{~h}$ [16]. This early improvement had a positive predictive value of 0.70 for a favorable 3-month outcome.

In conclusion, rapid complete recovery can be achieved in up to a fifth of acute-stroke patients treated with thrombolysis. These patients are younger and have milder strokes that are less often of cardioembolic origin. Better outcome and lower mortality are sustained at 3 months. 


\section{References}

1 Wilson JT, Hareendran A, Grant M, Baird T, Schulz UG, Muir KW, Bone I: Improving the assessment of outcomes in stroke: use of a structured interview to assign grades on the modified Rankin Scale. Stroke 2002;33: 2243-2246.

2 Wahlgren N, Ahmed N, Eriksson N, Aichner F, Bluhmki E, Dávalos A, Erilä T, Ford GA, Grond M, Hacke W, Hennerici MG, Kaste M, Köhrmann M, Larrue V, Lees KR, Machnig T, Roine RO, Toni D, Vanhooren G; Safe Implementation of Thrombolysis in StrokeMOnitoring STudy Investigators: Multivariable analysis of outcome predictors and adjustment of main outcome results to baseline data profile in randomized controlled trials: Safe Implementation of Thrombolysis in Stroke-MOnitoring STudy (SITS-MOST). Stroke 2008;39:3316-3322.

3 Demchuk AM, Tanne D, Hill MD, Kasner SE, Hanson S, Grond M, Levine SR; Multicentre tPA Stroke Survey Group: Predictors of good outcome after intravenous t-PA for acute ischemic stroke. Neurology 2001;57: 474-480.

4 Elkind MS, Prabharkaran S, Pittman J, Koroshetz W, Jacoby M, Johnston KC, GAIN Americas Investigators: Sex as a predictor of outcome in patients treated with thrombolysis for acute stroke. Neurology 2007;68:842848.
5 Delgado MG, Michel P, Naves M, Maeder P, Reichhart M, Wintermark M, Bogousslavsky J: Early profiles of clinical evolution after intravenous thrombolysis in an unselected stroke population. J Neurol Neurosurg Psychiatry 2010;81:282-285.

6 Kent DM, Buchan AM, Hill MD: The gender effect in stroke thrombolysis: of CASES, controls, and treatment-effect modification. Neurology 2008;71:1080-1083.

7 Kent DM, Price LL, Ringleb P, Hill MD, Selker HP: Sex-based difference in response to recombinant tissue plasminogen activator in acute ischemic stroke: a pooled analysis of randomized clinical trials. Stroke 2005;36: 62-65.

8 Saposnik G, Di Legge S, Webster F, Hachinski V: Predictors of major neurologic improvement after thrombolysis in acute stroke. Neurology 2005;65:1169-1174.

9 Tandberg Askevold E, Naess H, Thomassen L: Predictors for recanalization after intravenous thrombolysis in acute ischemic stroke. J Stroke Cerebrovasc Dis 2007;16:21-24.

10 Kimura K, Iguchi Y, Yamashita S, Shibazaki K, Kobayashi K, Inoue T: Atrial fibrillation as an independent predictor for no early recanalization after IV-t-PA in acute ischemic stroke. J Neurol Sci 2008;267:57-61.
11 Saňák D, Herzig R, Král M, Bártková A, Zapletalová J, Hutyra M, Skoloudík D, Vlachová I, Veverka T, Horák D, Kaňovský P: Is atrial fibrillation associated with poor outcome after thrombolysis? J Neurol 2010;257:9991003.

12 Kimura K, Iguchi Y, Shibazaki K, Iwanaga T, Yamashita S, Aoki J: IV t-PA therapy in acute stroke patients with atrial fibrillation. J Neurol Sci 2009;276:6-8.

13 Naess H, Idicula T, Lagallo N, Brogger J, Waje-Andreassen U, Thomassen L: Inverse relationship of baseline body temperature and outcome between ischemic stroke patients treated and not treated with thrombolysis: the Bergen stroke study. Acta Neurol Scand 2010;122:414-417.

14 Uchino K, Massaro L, Hammer MD: Transient ischemic attack after tissue plasminogen activator: aborted stroke or unnecessary stroke therapy? Cerebrovasc Dis 2010;29:5761.

15 Winkler DT, Fluri F, Fuhr P, Wetzel SG, Lyrer PA, Ruegg S, Engelter ST. Thrombolysis in stroke mimics: frequency, clinical characteristics, and outcome. Stroke 2009;40:15221525.

16 Brown DL, Johnston KC, Wagner DP, Haley EC Jr: Predicting major neurological improvement with intravenous recombinant tissue plasminogen activator treatment of stroke. Stroke 2004;35:147-150. 